\title{
THE INTERPRETATION OF TENSE IN DISCOURSE
}

\author{
Bonnie Lynn Webber \\ Department of Computer \& Information Science \\ University of Pennsylvania \\ Philadelphia PA 19104-6389
}

\begin{abstract}
This paper gives an account of the role tense plays in the listener's reconstruction of the events and situations a speaker has chosen to describe. Several new ideas are presented: (a) that tense is better viewed by analogy with definite NPs than with pronouns; (b) that a narrative has a temporal focus that grounds the context-dependency of tense; and (c) that focus management heuristics can be used to track the movement of temporal focus. ${ }^{1}$
\end{abstract}

\section{Introduction}

My basic premise is that in processing a narrative text, a listener is building up a representation of the speaker's view of the events and situations being described and of their relationship to one another. This representation, which I will call an event/situation structure or $\mathrm{e} / \mathrm{s}$ structure, reflects the listener's best effort at interpreting the speaker's ordering of those events and situations in time and space. The listener's problem can therefore be viewed as that of establishing where in the evolving e/s structure to attach the event or situation described in the next clause. My claim is that the discourse interpretation of tense contributes to the solution of this problem.

This work on the discourse interpretation of tense is being carried out in the context of a larger enterprise whose goal is an account of explicit anaphoric reference to events and situations, as in Example 1.

\section{Example 1}

It's always been presumed that when the glaciers receded, the area got very hot. The Folsum men couldn't adapt, and they died out. That's what's supposed to have happened. It's the textbook dogma. But it's wrong. They were human and smart. They adapted their weapons and culture, and they survived.

Example 1 shows that one may refer anaphorically to structured entities built up through multiple clauses. Thus an account of how clauses arrange themselves into structures is necessary to an account of event reference. ${ }^{2}$

\footnotetext{
'This work was partially supported by ARO grant DAA29-84-9-0027. NSF grant MCS-8219116-CER, and DARPA grant NO0014-85-K-0018 to the University of Pennsylvania, and by DARPA grant N00014-85-C-0012 to UNISYS.

2Other parts of the enterprise include a general mechanism for individuating composite entities made up of ones separately introduced $[20,21]$ and a representation for events that allow for anaphoric relerence to both particular events and situations and to abstractions thereof [16].
}

In this paper, I will relate the problem of building up an e/s structure to what has been described as the anaphoric property of tense $[7,11,6,1,12]$ and of relative temporal adverbials [18]. Anaphora are expressions whose specification is context-dependent. Tense and relative temporal adverbials, I interpret as specifying positions in an evolving e/s structure. My view of their anaphoric nature is that the particular positions they can specity depend on the current context. And the current context only makes a few positions accessible. (This I will claim to be in contrast with the ability of temporal subordinate clauses and noun phrases (NPs) to direct the listener to any position in the evolving structure.)

The paper is organized as follows: In Section 2, I discuss tense as an anaphoric device. Previous work in this area has discussed how tense is anaphoric, claiming as well that it is like a pronoun. While agreeing as to the source of the anaphoric character of tense, I do not think the analogy with pronouns has been productive. In contrast, I discuss what I believe to be a more productive analogy between tense and definite noun phrases.

Previous work has focussed on the interpretation of tensed clauses in simple linear narratives (i.e., narratives in which the order of underlying events directly corresponds to their order of presentation). ${ }^{3}$ Here the most perplexing question involves when the next clause in a sequence is interpreted as an event or sequence coincident with the previous one and when, as following the previous one $[4,6,12]$. In Section 3 , I show that if one moves beyond simple linear narratives, there are more options. In terms of the framework proposed here, there may be more than one position in the evolving e/s structure which can provide a context for the interpretation of tense. Hence there may be more than one position in e/s structure which tense can specify and which the new event or situation can attach to.

To model the possible contexts, 1 introduce a discourse-level focussing mechanism - temporal focus or TF - similar to that proposed for interpreting pronouns and definite NPs [17]. I give examples to show that change of TF is intimately bound up with narrative structure. To keep track of and predict its movement, I propose a set of focus heuristics: one Focus Maintenance Heuristic, predicting regular movement forward, two Embedded Discourse Heuristles for stacking the focus and embarking on an embedded narrative, and one Focus Resumption

\footnotetext{
${ }^{3}$ Another person currently addressing the interpretation of tense and aspect in more complex narratives is Nakhimovsky $[9,10]$. Though we are addressing somewhat different issues, his approach seems very compatible with this one.
} 
Heuristic for returning and resuming the current narrative. The need for each of these is shown by example.

In Section 4, I show that relative temporal adverbials display the same anaphoric property as simple tense.

That the interpretation of tense should be entwined with discourse structure in this way should not $\infty$ me as a surprise, as a similar thing has been found true of other discourse anaphora [5].

\section{Tense as Anaphor}

Tense does not seem prima facio anaphoric: an isolated sentence like "John went to bed" or "I met a man who looked like a basset hound" appears to make sense without previously establishing when it happened. On the other hand, if some time or event is established by the context, tense will invariably be interpreted with respect to it, as in:

\section{Example 2}

After he finished his chores, John went to bed.

John partiod until 3am. He came home and went

to bed.

In each case, John's going to bed is linked to an explictly mentioned time or event. This linkage is the anaphoric property of tense that previous authors have described.

Hinrichs [6] and Baverle [1], following McCawiey [7] and Partee [11], showed that it is not tense per se that is interpreted anaphorically, but that part of tense called by Reichenbach [14] reference time. ${ }^{4}$ According to Reichenbach, the interpretation of tense requires three notions: speech time (ST), event time (ET), and reference time (RT). RT is the time from which the event/situation described in the sentence is viewed. It may be the same as ST, as in

present perfect: $E T<R T=S T$

John has climbed Aconcagua and Mt. McKinley.

simple present: $E T=R T=S T$

John is in the lounge.

the same as ET, as in

simple past: $E T=R T<S T$

John climbed Aconcagua.

simple future: ST<ET=RT

John will climb Aconcagua.

in between ET and ST, as in

past perfect: $E T<R T<S T$

John had climbed Aconcagua.

or following both ET and ST (looking back to them), as in

'Hinnichs' work is discussed as well in [12]. future perfect: $S T<E T<R T$

John will have climbed Mt. McKinley.

That it is RT that it is interpreted anaphorically, and not either ET or tense as a whole can be seen by considering Example 3.

\section{Example 3}

John went to the hospital.

He had twisted his ankle on a patch of ice.

It is not the ET of John's twisting his ankle that is interpreted anaphorically with respect to his going to the hospital. Rather, it is the RT of the second clause: its ET is interpreted as prior to that because the clause is in the past perfect tense (se日 above).

Having said that it is the RT of tense whose interpretation is anaphoric, the next question to ask is what kind of anaphoric behavior it evinces. In previous work, tense is claimed to behave like a pronoun. Partee [12] makes the strongest case, claiming that pronouns and tense display the same range of antecedent-anaphor linkages:

Deictic Antecedents

pro: She left mel (said by a man crying on the stoop) ${ }^{5}$

tense: I left the oven on! (said by a man to his wife in the car)

Indefinite Antecedents

pro: I bought a banana. I took it home with me.

tense: I bought a banana. I took it home with me. $<$ l took it home after I bought it.>

Bound Variables

pro: Every man thinks he is a genius.

tense: Whenever Mary phoned, Sam was asleep.

$<$ Mary phoned at time t, Sam was asleep at $\Delta$

\section{Donkey Sentences}

pro: Every man who owns a donkey beats it.

tense: Whenever Mary phoned on a Friday, Sam was

asleep.

<Mary phoned at time ton a Friday, Sam was asleep at $t$ on that Fridays

Because of this similarity, Partee and others have claimed that tense is like a pronoun. Their account of how time is then seen to advance in simple linear narratives is designed, in part, to get around the problem that while pronouns co-specify with their antecedents, the RT of clause $N$ cannot just co-specify the same time as the previous clause $[6,12,4]$.

There is another option though: one can draw an analogy between tense and definite NPs, which are aiso anaphoric. Support for this analogy is that, like a definite

\footnotetext{
5I believe that the deictic use of pronouns is infelicitous. In this example, the speaker is distraught and making no attempt to be cooperative. It happens. But that doesn't mean that pronouns have deictic antecedents. I include the example here because it is part of Partee's argument.
} 
NP, tense can cause the listener to create something new. With a definite NP, that something new is a new discourse entity [19]. With tense, I will say for now that it is a new time at which the event or situation is interpreted as occuring. ${ }^{6}$ If one looks at texts other than simple linear narratives, this ability becomes clear, as the following simple example shows:

\section{Example 4}

I was at Mary's house yesterday.

We talked about her brother.

He spent 5 weeks in Alaska with two friends.

Together, they made a successful assault on Denali.

Mary was very proud of him.

The event of Mary's brother spending five weeks in Alaska is not interpreted as occurring either coincident with or after the event of my conversation with Mary. Rather, the events corresponding to the embedded narrative in the third and fourth clause are interpreted at a different spatiotemporal location than the conversation. That it is before the conversation is a matter of world knowledge. In the e/s structure for the whole narrative, the tense of the third clause would set up a new position for the events of the embedded narrative, ordered prior to the current position, to site these events.

The claimed analogy of tense with pronouns is based on the similarity in antecedent-anaphor linkages they display. But notice that definite NPs can display the same linkages in two different ways: (1) the definite NP can cospecify with its antecedent, as in the a. examples below, and (2) the definite NP can specify a new entity that is 'strongly' associated with the antecedent and is unique by virtue of that association, as in the $b$. examples below ${ }^{7}$

Deictic Antecedents

The car won't start! (said by a man crying on the stoop) Indefinite Antecedents

a. I picked up a banana. Up close, I noticed the banana was too green to eat.

b. I picked up a banana. The skin was all brown.

\section{Bound Variables}

a. Next to each car, the owner of the car was sleeping soundly.

b. In each car, the engine was idling quietly.

\section{Donkey Sentences}

a. Everyone who wants a car must fix the car himself.

b. Everyone who owns a Ford tunes the engine himself.

Thus the range of antecedent-anaphor behavior that Partee calls attention to argues equally for an analogy between tense and pronouns as for an analgoy between tense and definite NPs.

\footnotetext{
'After I say more about a/s structure construction, I will be able to claim that tense can cause the listener to create a new position in e/s structure at which to attach the event or sixuation described in its associated clause.

${ }^{7}$ Clark \& Marshall [2] are among those who have described the necessary "common knowledge" that must be assumable by speaker and listener about the association for the specification to be successful.
}

However, there are two more features of behavior to consider: On the one hand, as noted earlier, definite NPs have a capability that pronouns lack ${ }^{8}$. That is, they can introduce a new entity into the discourse that is 'strongly' associated with the antecedent and is unique by virtue of that association, as in the b. examples above. Example 4 shows that tense has a similar ability. Thus, a stronger analogy can be drawn between tense and definite NPs.

On the other hand, definite NPs have the capability to move the listener away from the current focus to a particular entity introduced earlier or a particular entity associated with it. This ability tense lacks. While tense can set up a new node in e/s structure that is strongly associated with its 'antecedent', it does not convey sufficient information to position that node precisely - for example, precisely relative to some other event or situation the listener has been told about. Thus its resemblance to definite NPs is only partial, although it is stronger-than its resemblance to pronouns. To locate a node precisely in $\theta / s$ structure requires the full temporal correlate of a definite NP - that is, a temporal subordinate clause or a definite NP itself, as in Example 5.

\section{Example 5}

The bus reached the Stadium, terminal for the suburban bus services. Here $\mathrm{De}$ Witt had to change to a streetcar. The wind had abated but the rain kept falling, almost vertically now. He was travelling to a two o'clock appointment at Amsterdam police headquarters in the center of town, and he was sure to be late.

When De Witt got to the police president's office, he telephoned his house.

[adapted from Hans Koning, De Witt's War]

Notice that without the "when" clause, the simple past tense of "he telephoned his house" would be anaphorically interpreted with respect to the "reaching the Stadium" event, as happening sometime after that. A new node would be created in e/s structure ordered sometime after the "reaching the Stadium" event. On the other hand, with the "when" clause, that new node can be ordered more precisely after the "reaching the Stadium" event. By association with its "antecedent" (the "travelling to the appointment" event), it can be ordered after the achievement of that event.

There is another advantage to be gained by pushing further the analogy between tense and definite NPs that relates to the problem tackled in $[6,4,12]$ of how to reconcile the anaphoric nature of tense with the fact that the event or situation described in the next clause varies as to whether it is taken to be coincident with, during, before or after the event or situation described in the previous clause. This I will discuss in the next section, after introducing the notion of temporal focus.

\footnotetext{
"except for "pronouns of laziness" which can evoke and specify new entities through the use of previous descriptions
} 


\section{Temporal Focus}

In this section, I give a more specific account of how the discourse interpretation of tense relates to $e / s$ structure construction.

At any point $N$ in the discourse, there is one node of a/s structure that provides a context for the interpretation of the RT of the next clause. I will call it the temporal focus or TF. There are three possibilities: (1) the RT of the next clause will be interpreted anaphorically against the current TF, (2) the TF will shift to a different node of a/s structure. - either one already in the structure or one created in recognition of an embedded narrative - and the RT interpreted with respect to that node, or (3) the TF will retum to the node previously labeiled TF, after completing an embedded narrative, as in (2), and the RT interpreted there. These three behaviors are described by four focus management heuristics described in this section: a focus Maintenance Heuristlc, two Embedded Discourse Heuristics and a Focus Resumption Heuristlc. ${ }^{9}$

In [21], I presented a control structure in which these heuristics were applied serially. The next heuristic would only be applied when the prediction of the previous one was rejected on grounds of "semantic or pragmatic inconsistency". I now believe this is an unworkable hypothesis. Maintaining it requires (1) identifying grounds for such rejection and (2) arguing that one can reject proposals, independent of knowing the alternatives.

I now don't believe that either can be done. It is rarely the case that one cannot come up with a story linking two events and/or situations. Thus it would be impossible to reject a hypothesis on grounds of inconsistency. All one can say is that one of such stories might be more plausible than the others by requiring, in some sense not explored here, fewer interences. ${ }^{10}$

Thus I would now describe these heuristics as running in parallel, with the most plausible prediction being the one that ends up updating both e/s structure and the TF. For clarity in presentation though, I will introduce each heuristic separately, at the point that the next example calls for it.

\subsection{Interpreting RT against TF}

Before presenting the temporal focus management heuristics, I want to say a bit more about what it can mean to interpret the RT of the next clause against the current TF. This discussion points out the additional advantage to

\footnotetext{
${ }^{9}$ Rohrer [15] suggests that there may exist a set of possible temporal reterents, possibly ordered by saliency, among which the tense in a sentence may find its reterence time, but doesn't elaborate how. That is the oniy thing I have seen that comes close to the current proposal.

${ }^{10}$ Crain and Steodman [3] make a similar argument about prepositional phrase (PP) artactiment. For example, it is not impossible for a cat to own a relescope - e.9., by inheritance from its fomer owner. Thus "a cat with a telescope" is not an inconsistent description. However, it must compete with other plausible interpretations like "seeing with a telescope" in "I saw a cat with a telescope".
}

be gained by pushing the analogy between tense and definite NPs.

As I noted above, a definite NP can specify an entity 'strongly' associated with its antecedent. One might thus consider what is 'strongly' associated with an event. One answer to this question appears in two separate papers in this volume $[8,13]$, each ascribing a tripartite structure to the way we view and talk about events. This structure consists of a preparatory phase, a culmination, and a consequence phase, to use the terminology of [8]. (Such a structure is proposed, in par, to give a uniform account of how the interpretation of temporal adverbials interacts with the interpretation of tense and aspect.)

Nodes in e/s structure correspond to events and situations, as the speaker conceives them. If one associates such a structure with the node labelled the current TF, then one can say that 'strongly' associated with it are events and situations that could make up its preparatory phase, culmination or consequence phase. Like a definite NP, the RT of tense may either co-specify the current TF or set up a new node in e/s structure 'strongly' associated with the TF. In the latter case, its corresponding event or situation will be interpreted as being part of one of these three phases, depending on the speaker and listener's assumed shared knowledge. Since, arguably, the most common way of perceiving the worid is as an ordered sequence of events, this will increase the plausibility of interpreting the next event or situation as (1) still associated with the current TF and (2) part of the consequence phase of that event (i.e., after it). On the other hand, this 'strong association' treatment no longer limits anaphoric interpretation to "co-specify" or "right after" as in $[4,6,12]$. The event described can be anaphorically associated with the the whole event structure (Example 6a), the consequence phase (Example $6 b$ - "right after"), or the preparatory phase (Example $6 c$ before").

\section{Example 6}

a. John walked across lowa. He thought about Mary, who had run off with a computational linguist.

b. John walked across lowa. He crossed the state line at Council Blutts and headed west through Nebraska.

\section{c. John walked across lowa. He started in Sioux City and headed east to Fort Dodge.}

Deciding which of these three options holds in a given case demands an appeal to world knowledge (e.g. which actions can be performed simultaneously by a single agent). This is yet another area demanding further study and is not treated in this paper. ${ }^{11}$

\footnotetext{
"Mark Steodman shares responsibility for this idea, which is also mentioned in his paper with Marc Moens in this volume [8].
} 


\subsection{Focus Maintenance and Focus Movement}

The following pair of examples illustrate the simplest movement of temporal focus in a discourse and its link with e/s structure construction.

\section{Example 7a}

1. John went over to Mary's house.

2. On the way, he had stopped by the flower shop for some roses.

3. Unfortunately the roses failed to cheer her up.

\section{Example 7b}

1. John went over to Mary's house.

2. On the way, he had stopped by the flower shop for some roses.

3. He picked out 5 red ones, 3 white ones and one pale pink.

Since the first two clauses are the same in these examples, I will explain them together.

With no previous temporal focus (TF) established prior to clause 1, the listener creates a new node of e/s structure, ordered prior to now, to serve as TF. TF sites the anaphoric interpretation of $\mathrm{RT}_{1}$, which, because clause 1 is in the simple past, also sites ET. This is shown roughly in Figure 3-1.

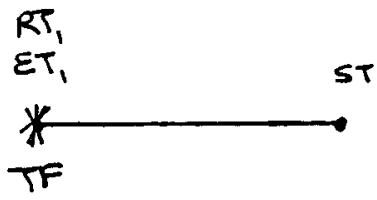

Flgure 3-1: E/S structure after processing clause 1

The first heuristic to be introduced is a Focus Maintenance Heurlstic (FMH).

After interpreting clause $N$, the new TF is the most recent TF - i.e., the node against which $R_{N}$ was interpreted.

The most recent TF is cotemporal with $R T_{1}$. This new TF now provides a site for interpreting $R T_{2}$. Since clause 2 is past perfect, $E T_{2}$ is interpreted as being prior to $R T_{2}$. E/s structure is now roughly as shown in Figure 3-2.

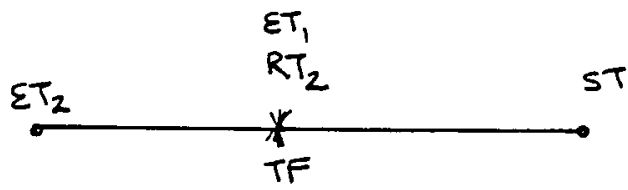

Figure 3-2: $E / S$ structure after processing clause 2

Applying the FMH again, $\mathrm{RT}_{2}$ is the new TF going into clause 3. Examples $7 a$ and $7 b$ here diverge in what subsequently happens to the TF.

In $7 \mathrm{a}, \mathrm{RT}_{3}$ can be anaphorically interpreted as immediately following the TF. Since $R T_{3}$ in turn directly sites $E T_{3}$ (clause 3 being simple past), the "failing event" is interpreted as immediately following the "going over to Mary's house" event. This is shown roughly in Figure 3-3. (TF is shown aiready moved forward by the FMH, ready for the interpretation of the rext clause, if any.)

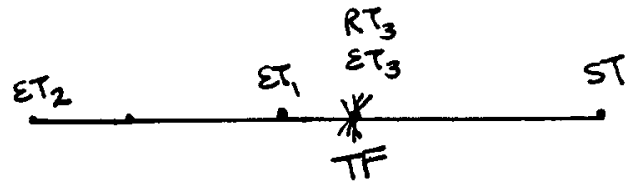

Figure 3-3: E/S structure after processing clause 7a-3

To get the most plausible interpretation of $7 \mathrm{~b}$ - i.e. where the "rose picking" event is interpreted anaphorically with respect to the "flower shop" event - requires a second houristic, which I will call an Embedded Discourse Heuristlc. This will be EDH-1, since I will introduce another Embedded Discourse Heuristic a bit later.

If $E T_{N}$ is different from $R T_{N}=T F$, treat utterance $N$ as the beginning of an embedded narrative, reassign $E T_{N}$ to TF (stacking the previous value of TF, for possible resumption later) and try to interpret $R T_{N+1}$ against this now TF.

By this heuristic winning the plausibility stakes against the $F M H, T F$ is reassigned to $E T_{2}$ (stacking the previous TF, which is sited at $R T_{2}=R T_{1}=E T_{1}$ ), and $R T_{3}$ is anaphorically interpreted as following this new TF. As before, $\mathrm{ET}_{3}$ is sited directly at $R T_{3}$ (since simple past), so the "picking out the roses" event is viewed as immediately following the "stopping at the florist" event. This is shown roughly in Figure 3-4.

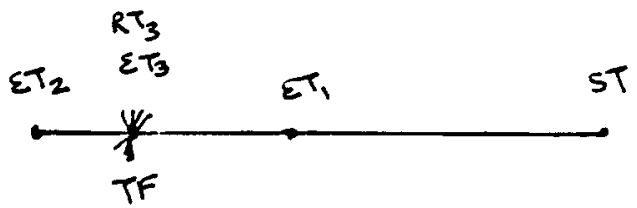

Figure 3-4: E/S structure after processing clause 7b-3

Now consider the following extension to example $7 \mathrm{~b}$. Example 7c

1. John went over to Mary's house.

2. On the way, he had stopped by the flower shop for some roses.

3. He picked out 5 red ones, 3 white ones and one pale pink.

4. Unfortunately they failed to cheer her up.

First notice that clauses $2-3$ form an embedded narrative that interrupts the main narrative of John's visit to Mary's. The main sequence of events that begins with clause 1 resumes at clause 4. Now consider the anaphoric interpretation of tense. Clauses 1-3 are interpreted as in Example $7 b$ (cf. Figure 3-4). The problem comes in the interpretation of Clause 7c-4. 
To get the most plausible interpretation requires a third heuristic which I will call a Focus Resumption Heuristic (FRH).

At the transition back from an embedded narrative, the TF prior to the embedding (stacked by an Embedded Dlscourse Houriatlc) can be resumed.

Using this heuristic, the previously stacked TF (sited at $R T_{2}=R T_{1}=E T_{1}$ - the "going to Mary's house" event) becomes the new TF, and $\mathrm{RT}_{4}$ is interpreted as directly following it. Since clause 7c-4 is simple past, the "failing" ovent is again correctly interpreted as immediately following the "going over to Mary's house" event. This is shown roughly in Figure 3-5.

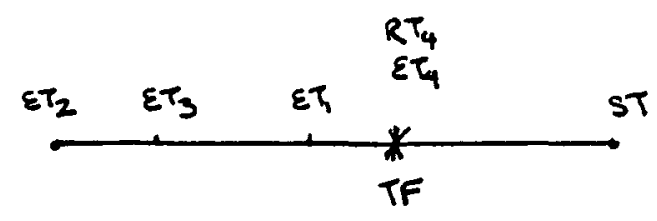

Figure 3-5: ES structure after processing clause 7c-4

I have already noted that, like a definite NP, tense can cause the listener to create a new node in e/s structure to site its RT. What I want to consider here is the circumstances under which a reader is likely to create a new node of $e / 8$ structure to interpret $R T_{N+1}$, rather than using an existing node (i.e., the current TF, one associated with the previous event (if not the TF) or a previous, stacked TF).

One circumstance 1 mentioned earlier was at the beginning of a discourse: a reader will take an introductory sentence like Snoopy's famous first line

It was a dark and stormy night.

and start building up a new e/s structure with one node corresponding to ST and another node siting RT and ET. Generalizing this situation to the beginning of embedded narratives as well, I propose a second Embedded Discourse Heuristic (EDH-2):

If clause $\mathrm{N}+1$ is interpreted as beginning an embedded narrative, create a new node of e/s structure and assign it to be TF. Stack the previous value of TF, for possible resumption later.

EDH-2 differs from EDH-1 in being keyed by the new clause itself: there is no existing event node of $\theta / 3$ structure, different from the current TF, which the embedded narrative is taken to further describe.

EDH-2 explains what is happening in interpreting the third clause of Example 4. Even though all the clauses of Example 4 are simple past, with ET=RT, the third clause is most plausibly interpreted as describing an event which has occured prior to the "teiling about her brother" event. EDH-2 provides the means of interpreting the tense in an embedded narrative whose events may occur either before or even atter the current TF.

\section{Example 4}

1. I was at Mary's house yesterday.

2. We talked about her brother.

3. He spent 5 weeks in Alaska with two friends.

4. Together, they made a successful assault on Denali.

5. Mary was very proud of him.

Notice that the focus stacking specified in EDH-2 enables the correct interpretation of clause 4-5, which is most plausibly interpreted via the FRH as following the telling about her brother" event.

EDH-2 is also relevant for the interpretation of NPS headed by de-verbal nouns (such as "trip", "installation", etc.). While such a NP may describe an event or situation, there may not be enough information in the NP itself or in its clause to locate the event or situation in e/s structure (ct. "my trip to Alaska" versus "my recent/upcoming trip to Alaska"). On the other hand, EDH-2 provides a way of allowing that information to come from the subsequent discourse. That is, if the following clause or NP can be interpreted as describing a particular event/situation, the original NP and the subsequent NP or clause can be taken as co-specifying the same thing. Roughly, that is how I propose treating cases such as the following variation of Example 4:

\section{Example 8}

1. I was talking with Mary yesterday.

2. She told me about her trip to Alaska.

3. She spent five weeks there with two friends, and the three of them climbed Denali.

The NP "her trip to Alaska" does not of itself cause an addition to $\mathrm{e} / \mathrm{s}$ structure. ${ }^{12}$ Rather, application of EDH-2 to the interpretation of clause 5-3 results in the creation of a new node of a/s structure against which its RT is sited. Other reasoning results in clause 3 and "her trip to Alaska" being taken as co-specitying the same event. This is what binds them together and associates "her trip to Alaska" with a node of e/s structure.

Finally, notice that there will be an ambiguity when more than heuristic makes a plausible prediction, as in the following example:

Example 9

1. I told Frank about my meeting with Ira.

2. We talked about ordering a butterfly.

It is plausible to take the second utterance as the beginning of an embedded narrative, whereby EDH-2 results in the "talking about" event being interpreted against a new node of e/s structure, situated prior to the telling Frank" event. (In this case, "we" is Ira and me.) It is also plausible to take the second utterance as continuing the current narrative, whereby FMH results in the "talking about" event being interpreted with respect to the "telling Frank" event. (In contrast here, "we" is Frank and me.)

\footnotetext{
12 it does, of course, resuit in the creation of a discourse entry [19]. The relationstip I see berween the listener's a/s structure and hisher dlecourse model is discussed in [21].
} 


\section{Temporal Focus and Temporal Adverbials}

So far I have only shown that clauses containing no other time-related constructs than tense can be interpreted anaphorically against more than one site in e/s structure. Now I want to show, at least by example, that what I have proposed holds for clauses containing relative temporal adverbs as well. Relative temporal adverbials must be interpreted with respect to some other time [18]. So consider the italicized forms in the following brief texts.

John became the captain of Penn's squash team.

He was previously captain of the Haverford team.

John left for London on Sunday.

Tuesday he went to Cambridge.

Tuesday John went to Cambridge.

On Sunday, he left for London.

Previously is interpreted with respect to the previously mentioned "becoming captain" event: it was before that that he was captain at Haverford. In the second case, the adverbial On Sunday, given no previous link in the discourse, is interpreted with respect to ST. However, Tuesday is then interpreted with respect to the event of John's leaving for London: it is interpreted as the Tuesday after that event. The third case is the reverse.

What I want to show is that, as beiore, the same four heuristics predict the sites in $e / s$ structure that may provide a context for a relative temporal adverbial. Consider the following.

\section{Example 10a}

1. John went over to Mary's house.

2. On the way, he had stopped by the flower shop for some roses.

3. After five minutes of awkwardness, he gave her the flowers

\section{Example 10b}

1. John went over to Mary's house.

2. On the way, he had stopped by the flower shop for some roses.

3. After 20 minutes of waiting, he left with the bouquet and fairly ran to Mary's.

I will use ADV to refer to the interpretation of the "after" adverbial. In these cases, what is sited by TF is the beginning of the interval. What in turn sites the RT of the main clause is the end of the interval.

The processing of the first two clauses is just the same as in examples $7 a$ and $b$. From here, the two examples diverge.

In 10a-3, the beginning of ADV is most plausibly interpreted with respect to the TF. The end of ADV in turn provides an anaphoric interpretation point for $R T_{3}$. Since $E T_{3}$ is interpreted as coincident with $R T_{3}$ (clause 3 being simple past), the "rose giving" event is interpreted as immediately following John's getting to Mary's house. This is shown roughly in figure 4-1.

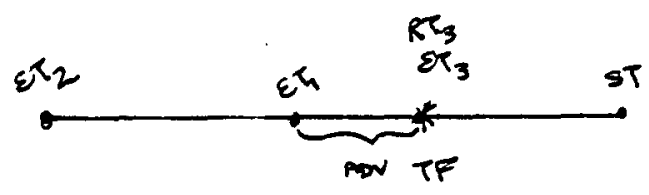

Figure 4-1: E/S structure after processing clause 10a-3

In 10b-3, the interpretation due to FMH is less plausible than that due to EDH-1. EDH-1 re-assigns TF to $E T_{2}$, where the beginning of ADV is then sited. The end of $A D V$ in turn provides an anaphoric interpretation point for $\mathrm{RT}_{3}$. Since $\mathrm{ET}_{3}$ is sited at $\mathrm{RT}_{3}$, the "leaving with the bouquet" event is sited at the end of the twenty minutes of waiting. This is shown roughly in Figure 4-2.

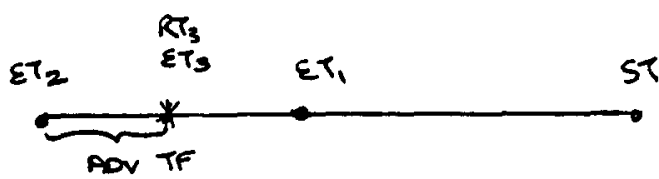

Figure 4-2: E/S structure after processing clause 10b-3

An interesting question to consider is whether a speaker would ever shift the TF as modelled by the FRH or the EDH-2, while simultaneously using a relative temporal adverbial whose interpretation would have to be linked to the new TF, as in example 11 (movement via FAH) and example 12 (movement via EDH-2).

\section{Example 11}

1. John went over to Mary's house.

2. On the way, he had stopped by the flower shop for some roses

3. He picked out 5 red ones, 3 white ones and one pale pink.

4. After 5 minutes of awkwardness, he gave her the flowers.

\section{Example 12}

1. I was at Mary's house yesterday.

2. We talked about her brother.

3. After 6 months of planning, he went to Alaska with two friends.

4. Together, they made a successful assault on Denali.

5. Mary was very proud of him.

I find both examples a bit awkward, but nevertheless understandable. Accounting for TF movement in each of them is straightforward. However, whether to attribute the awkwardness of these examples to exceeding people's processing capabilities or to a problem with the theory is grist for further study. 


\section{Conclusion}

In this paper, I have given what I believe to be a credible account of the role that tense plays in the listener's reconstruction of the events and situations a speaker has chosen to describe. I have provided support for several new ideas: (a) that tense is better viewed by analogy with definite NPs than with pronouns; (b) that a narrative has a temporal focus that grounds the contextdependency of tense; and (c) that focus management heuristics can be used to track the movement of temporal focus. I have also identified a host of problems that require further work, including (1) how to incorporate aspectual interpretation into the model, (2) how to evaluate 'strong associations' between events and/or situations and (3) how to judge plausibility.

\section{Acknowledgments}

I would like to extend my thanks to Debby Dahl, Martha Palmer and Becky Passonneau at UNISYS for their enthusiastic support and trenchant criticism. I have also gained tremendously from discussions with James Allen, Barbara Grosz, Erhard Hinrichs, Aravind Joshi, Hans Kamp, Ethel Schuster, Candy Sidner, and Mark Steødman.

\section{References}

1. Bauerte, R.. Temporale Deixis, temporale Frage. Gunter Narr Verlag, Tubigen, 1979.

2. Clark, H. \& Marshall, C. Definite Reference and Mutual Knowledge. In Elements of Discourse Understanding. A.K. Joshi, B.L. Webber \& I.A. Sag, Ed., Cambridge University Press, Cambridge England, 1981, pp. 10-63.

3. Crain, S. \& Steedman, M. On not being Led up the Garden Path: the use of context by the psychological syntax processor. In Natural Language Parsing, D. Dowty, L. Karttunen \& A. Zwicky, Ed., Cambridge Univ. Press, Cambridge England, 1985, pp. 320-358.

4. Dowty, D. The Effects of Aspectual Class on the Temporal Structure of Discourse: Semantics or Pragmatics". Linguistics and Philosophy 9, 1 (February 1986), 37-62.

5. Grosz, B. \& Sidner, C. Attention, Intention and the Structure of Discourse". Computational Linguistics 12, 3 (July-September 1986), 175-204.

6. Hinrichs, E. Temporal Anaphora in Discourses of English". Linguistics and Philosophy 9, 1 (Fobruary 1986), 63-82.

7. McCawley, J. Tense and Time Reference in English. In Studies in Linguistic Semantics, C. Fillmore \& D.T. Langendoen, Ed., Hot, Rinehart and Winston, Inc., New York, 1971, pp. 97-114.
8. Moens, M. \& Steedman, M. Temporal Ontology in Natural Language. Proc. of the 25th Annual Meeting, Assoc. for Computational Linguistics, Stanford Univ., Palo Alto CA, July, 1987. This volume..

9. Nakhimovsky, A. Temporal Reasoning in Natural Language Understanding. Proc. of EACL-87, European Assoc. for Computational Linguistics, Copenhagen, Denmark, April, 1987.

10. Nakhimovsky, A. Tense, Aspect and the Temporal Structure of the Narrative. Submitted to Computational Linguistics, special issue on computational approaches to tense and aspect.

11. Parteo, B. "Some Structural Analogies between Tenses and Pronouns in English". Journal of Philosophy 70 (1973), 601-609.

12. Partee, B. "Nominal and Temporal Anaphora". Linguistics and Philosophy 7, 3 (August 1984), 243-286.

13. Passonneau, R. Situations and Intervals. Proc. of the 25th Annual Meeting, Assoc. for Computational Linguistics, Stanford Univ., Palo Alto CA, July, 1987. This volume.

14. Reichenbach, H.. The Elements of Symbolic Logic. The Free Press, Now York, 1966. Paperback edition.

15. Rohrer, C. Indirect Discourse and 'Consecutio Temporum'. In Temporal Structure in Sentence and Discourse, V. Lo Cascio \& C. Vet, Ed., Foris Publications, Dordrecht, 1985, pp. 79-98.

16. Schuster, E. Towards a Computational Model of Anaphora in Discourse: Reference to Events and Actions. CIS-MS-86-34, Dept. of Comp. \& Into Science, Univ of Pennsylvania, June, 1986. Doctoral thesis proposal.

17. Sidner, C. Focusing in the Comprehension of Definite Anaphora. In Computational Models of Discourse, M. Brady \& R. Berwick, Ed., MIT Press, Cambridge MA, 1982, pp. 267-330.

18. Smith, C. Semantic and Syntactic Constraints on Temporal Interpretation. In Syntax and Semantics, Volume 14: Tense \& Aspect, P. Tedesci \& A. Zaenen, Ed., Academic Press, 1981, pp. 213-237.

19. Webber, B.L. So What Can We Talk about Now? In Computational Models of Discourse, M. Brady \& R. Berwick. Ed., MIT Press, Cambridge MA, 1982, pp. 331-371.

20. Webber, B.L. Event Reference. Theoretical Issues in Natural Language Processing (TINLAP-3), Assoc. for Computational Linguistics, Las Cruses NM, January, 1987. pp. 137-142.

21. Webber, B.L. Two Steps Closer to Event Reference. ClS-86-74, Dept. of Comp. \& Info Science, Univ. of Pennsylvania, February, 1987. 